See Article page 1804.

\section{Commentary: Transcatheter mitral valve-in-valve: Not yet a replacement for surgery}

\author{
J. James Edelman, PhD, FRACS, ${ }^{a}$ and \\ Vinod H. Thourani, MD
}

Javadikasgari and colleagues ${ }^{1}$ report the experience of mitral valve re-replacement for structural valve deterioration at the Cleveland Clinic over 27 years. A total of 525 patients with a mean age of 67 years had a second mitral valve replacement (MVR): isolated redo-MVR in $25 \%$ and with concomitant procedures in $75 \%$. The results are outstanding, with mortality $<0.75 \%$ for isolated redo-MVR and $7.1 \%$ for those with concomitant procedures. The authors identify New York Heart Association functional class IV symptoms, concomitant coronary artery bypass grafting, prolonged cardiopulmonary bypass time, and transfusion as independent risk factors for mortality. Ten-year survival for isolated redo-MVR and redo-MVR with concomitant procedures was $52 \%$ and $48 \%$, respectively.

This article raises a number of important points. The ratio of observed mortality to that expected from the Society of Thoracic Surgeons Database was 0.12. This underscores that national estimated percentages cannot always be generalized to high-volume centers that are commonly performing these risky procedures compared with smaller programs in which redo-MVR may be done a couple of times a year. In fact, just looking at US centers performing primary, isolated MV repair, only $13 \%$ perform 10 or more procedures per year. ${ }^{2}$ Secondly, the patient cohort in the current series is relatively young and may represent a very select group of patients because no data are available on the proportion of patients either not offered redo-MVR or those who went

\footnotetext{
From the a Department of Cardiothoracic Surgery, Fiona Stanley Hospital, University of Western Australia, Perth, Australia; and ${ }^{\mathrm{b}}$ Department of Cardiovascular Surgery, Marcus Valve Center, Piedmont Heart Institute, Atlanta, Ga.

Disclosures: The authors reported no conflicts of interest.

The Journal policy requires editors and reviewers to disclose conflicts of interest and to decline handling or reviewing manuscripts for which they may have a conflict of interest. The editors and reviewers of this article have no conflicts of interest.

Received for publication Aug 31, 2020; revisions received Aug 31, 2020; accepted for publication Sept 1, 2020; available ahead of print Sept 4, 2020.

Address for reprints: Vinod H. Thourani, MD, Department of Cardiovascular Surgery, Marcus Valve Center, Piedmont Heart Institute, 95 Collier Rd, Suite 5015, Atlanta, GA 30308 (E-mail: vinod.thourani@piedmont.org).

J Thorac Cardiovasc Surg 2022;163:1813-4

$0022-5223 / \$ 36.00$

Copyright (c) 2020 by The American Association for Thoracic Surgery

https://doi.org/10.1016/j.jtcvs.2020.09.005
}

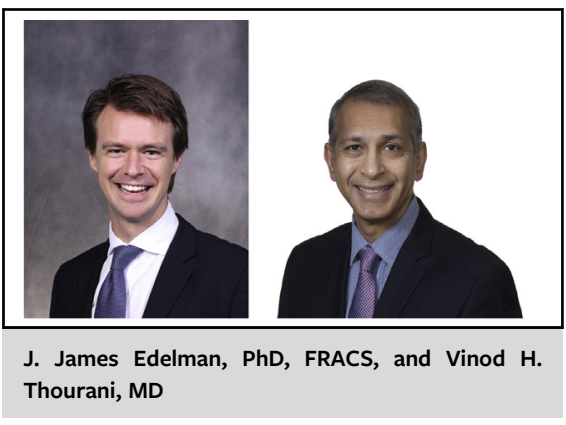

CENTRAL MESSAGE

Reoperative mitral valve replacement can be performed with excellent results in some centers. Additionally, transcatheter mitral valve-in-valve offers high-risk patients an opportunity for treatment.

the way of transcatheter valve therapies. An older cohort of patients (mean age, 78 years) undergoing redo-valvular surgery at another high-volume expert center reported an operative mortality of $10 \% .^{3}$

The experience in transcatheter mitral valve-in-valve (ViV) replacement is early. The procedure is safe, but long-term data are lacking. Furthermore, those patients with a previous mechanical mitral valve prosthesis or those with a narrow postimplant neo-left ventricular outflow tract will be excluded from transcatheter therapeutic options. A comparison of surgical redo-MVR and transcatheter mitral $\mathrm{ViV}$ has demonstrated similar early mortality, albeit in groups with different risk profiles. ${ }^{4}$ Surgical redo-MVR patients had a lower transvalvular gradient at 1 year. This has mirrored the enormous enthusiasm for transcatheter aortic valve replacement $\mathrm{ViV}$ as an alternative for redo-surgical aortic valve replacement in the setting of failed bioprostheses. Recent publications with $>5$-year follow-up have supported the early safety of this approach but longterm data highlight that not all bioprosthetic structural valve deterioration is best treated with transcatheter aortic valve replacement ViV; especially, those with small failed surgical prostheses.,

Until a randomized trial is performed, it is going to be very difficult to determine the relative efficacy of redovalvular surgery compared with a transcatheter approach. The increasing availability of transcatheter mitral ViV 
procedures offers those who are high-risk for redo-surgery-or are inoperable-an opportunity for treatment. For patients who are of low or intermediate risk, heart teams must debate the relative efficacies of each approach, acknowledging the excellent outcomes of redo-surgery available at some centers together with the unknown longterm results of $\mathrm{ViV}$ procedures.

\section{References}

1. Javadikasgari H, Chemtob RA, Gillinov AM, Pettersson GB, Lowry AM, Desai MY, et al. Outcomes of mitral valve re-replacement for bioprosthetic structural valve deterioration. J Thorac Cardiovasc Surg. 2022;163:1804-12.e5.
2. Gammie JS, Chikwe J, Badhwar V, Thibault DP, Vemulapalli S, Thourani VH, et al. Isolated mitral valve surgery: the Society of Thoracic Surgeons Adult Cardiac Surgery Database analysis. Ann Thorac Surg. 2018;106:716-27.

3. Maganti M, Rao V, Armstrong S, Feindel CM, Scully HE, David TE. Redo valvular surgery in elderly patients. Ann Thorac Surg. 2009;87:521-5.

4. Kamioka N, Babaliaros V, Morse MA, Frisoli T, Lerakis S, Iturbe JM, et al. Comparison of clinical and echocardiographic outcomes after surgical redo mitral valve replacement and transcatheter mitral valve-in-valve therapy. JACC Cardiovasc Interv. 2018;11:1131-8.

5. Deharo P, Bisson A, Herbert J, Lacour T, Etienne CS, Porto A, et al. Transcatheter valve-in-valve aortic valve replacement as an alternative to surgical re-replacement. J Am Coll Cardiol. 2020;76:489-99.

6. Bleiziffer S, Simonato M, Webb JG, Rodés-Cabau J, Pibarot P, Kornowski R, et al. Long-term outcomes after transcatheter aortic valve implantation in failed bioprosthetic valves. Eur Heart J. 2020;41:2731-42.
See Article page 1804

\section{Commentary: Doing it and (re) doing it well}

\section{Tomasz A. Timek, MD, PhD}

Mitral valve replacement in the United States still represent of $34 \%$ of isolated mitral valve procedures with $70 \%$ of implanted prostheses being bioprosthetic valves. ${ }^{1}$ Unfortunately, mitral bioprostheses have limited durability, yet reoperative mitral valve surgery has been associated with increased morbidity and mortality with some reports advocating use of mechanical valves for patients younger than age 70 years. $^{2}$ Transcatheter valve technologies have been developed to mitigate the risk of valvular surgery for prohibitive- and high-risk patients, with recent expansion of indications for valve-in-valve treatment of structural deterioration of mitral bioprostheses. ${ }^{3}$ Although short term-outcomes of this treatment strategy have been encouraging, ${ }^{3}$ distant results are lacking. To best define treatment pathways for patients with failed mitral bioprosthetic

From the Division of Cardiothoracic Surgery, Spectrum Health, Michigan State University College of Human Medicine, Grand Rapids, Mich.

Disclosures: The author reported no conflicts of interest.

The Journal policy requires editors and reviewers to disclose conflicts of interest and to decline handling or reviewing manuscripts for which they may have a conflict of interest. The editors and reviewers of this article have no conflicts of interest.

Received for publication Sept 11, 2020; revisions received Sept 11, 2020; accepted for publication Sept 11, 2020; available ahead of print Sept 17, 2020.

Address for reprints: Tomasz A. Timek, MD, PhD, Division of Cardiothoracic Surgery, Spectrum Health, Michigan State University College of Human Medicine, 100 Michigan Ave NE, Grand Rapids, MI 49503 (E-mail: tomasz.timek@ spectrumhealth.org).

J Thorac Cardiovasc Surg 2022;163:1814-5 $0022-5223 / \$ 36.00$

Copyright $₫ 2020$ Published by Elsevier Inc. on behalf of The American Association for Thoracic Surgery

https://doi.org/10.1016/j.jtcvs.2020.09.046

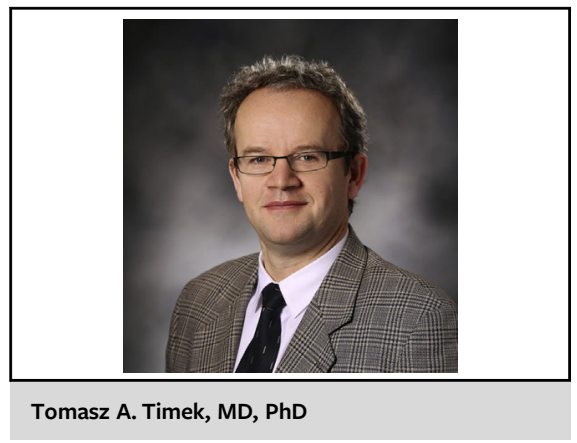

CENTRAL MESSAGE

Mitral valve re-replacement for

bioprosthetic structural valve

deterioration in selected patients

can be performed with very

good perioperative and long-

term survival.

valves, reoperative surgical risk needs to be benchmarked versus less invasive but potentially less durable transcatheter therapies. Javadikasgari and colleagues ${ }^{4}$ from the Cleveland Clinic present a large cohort of 525 patients who underwent bioprosthetic mitral valve re-replacement for structural valve deterioration. The authors should be congratulated on very low mortality of only $0.75 \%$ in the isolated valve replacement subgroup, $7.1 \%$ mortality for combined procedures, and impressive long-term survival of approximately $50 \%$ at 10 years.

Although the outcomes for patients undergoing combined procedures are quite good, the outstanding results in 